\title{
Calculating a Realistic Security Bond and Assessing True Mine Closure Liabilities
}

\author{
M. Woolley URS Australia Pty Ltd, Australia
}

A. Hutton GSS Environmental, Australia

\section{INTRODUCTION}

During the 1990s a number of mine operators in NSW, Australia became insolvent and mining leases, along with the closure and rehabilitation liabilities, were passed back to the government. In many cases it was found that the Security Bond held by the government represented only a small portion of the actual amount required to effectively close the operations to appropriate environmental and public safety standards. Accordingly, where no alternative was identified, these mines were managed by the Department of Primary Industries - Mineral Resources (DPI-MR) as part of their Derelict Mines Program (DMP). Even when supplemented by DMP funds, there was frequently insufficient money for full or even adequate rehabilitation and the works undertaken were generally to make the site safe.

Derelict mines continue to burden NSW taxpayers as well as being a public safety and environmental risk. Their legacies arguably represent a risk to the mining industries public licence to operate and to the image of sustainable mining practices throughout Australia generally.

With the aim of investigating potential underlying causes for the failure of the government to hold sufficient security for closure, the DPI-MR commissioned URS to undertake a study into their security review process including benchmarking of processes against other agencies in Australia and worldwide. A number of findings were made, including that the majority of agencies did not hold sufficient securities to cover potential mine closure liabilities.

A key recommendation was that mine operators should have the responsibility for "self assessment" of the total costs required for rehabilitation and closure of the mine. Operator cost estimates would then be reviewed by the DPI-MR and set as the security bond for the operation.

Consequently a Rehabilitation Cost Estimate Tool was developed by URS/GSSE to enable a thorough and consistent approach for all NSW mine sites to use in the estimation of closure liabilities. The cost estimation approach would form a minimum standard for establishing an appropriate security bond for the site.

The Tool is now being used as a basis for closure cost assessment in NSW and following some modification, is currently being trial for use by the Victorian DPI in their management of mines and extractive industries.

This paper explores the inaccuracies of past bond estimation methodologies, particularly in relation to the under estimation of the security bonds and also includes the findings of the benchmarking review. A summary is provided of the approach taken in development of the Rehabilitation Cost Estimate Tool for NSW as well as discussion on how the Tool was modified to fit the Victorian context. In conclusion, recommendations are made for the industry going forward based on the feedback from the state agencies, industry groups and the mine operators alike.

\section{SECURITY BOND ESTIMATIONS - HOW ACCURATE ARE THEY?}

As part of the study, three mines in NSW were reviewed to provide insight into the security bond process and to identify the cause of lower than required security bonds.

In the first example, a mine located to the south of NSW was operated from 1986 to 1996 with the site experiencing a number of difficulties associated with landforms and acid mine drainage. The initial security bond requirement was A $\$ 245,000$ (1986), but following a review in 1993 it was recommended that the bond be increased to A $\$ 1.5$ million. During subsequent negotiations, the bond was reduced to $A \$ 500,000$ and a 
work plan of progressive rehabilitation was agreed. Recommendations by the DPI-MR were made in 1995 and 1996 to increase the bond to A $\$ 750,000$, however, this security amount was never received. The company filed for bankruptcy during rehabilitation at which point it was stated that A $\$ 1.5$ million had been spent to date. The final rehabilitation costs were unknown. It is expected that the site will continue to be affected by acid mine drainage in the long term.

In a second example the major shareholder of a gold mine called in receivers in early 2002. The operation was generally viewed to be a marginal operation and subsequently decisions to increase security were understood to have implications for the viability of the mine. Security bond reviews, were initially conducted with some frequency (between 1992 and 1998). After 1998, the next review occurred in February 2001 when it was recommended to increase the bond from $\mathrm{A} \$ 342,000$ to $\mathrm{A} \$ 671,000$. It was also recommended that the bond be increased to A $\$ 1$ million based on 1998 expansion plans. In Oct 2001, the AEMR was reviewed and in response to unpredicted expansion, and it was recommended that the security be increased to A $\$ 1.75$ million. A request was made by the site operators in December 2001 for reconsideration of the security bond, which was rejected. In early 2002 the company went into administration. Following mine closure, actual rehabilitation liabilities were estimated to be well in excess of A $\$ 1.75$ million.

The third example is of a colliery located to the south of Sydney that closed and the operators forfeited their security to the DPI-MR. The security bond was reported to be approximately $10 \%$ of actual rehabilitation costs. The difference between the bond amount and closure costs occurred due to:

- In the original assessment of closure costs for the facility by the DPI-MR was assumed that infrastructure at pit top had some value. This value was not realised on closure as no one wanted to buy the remaining equipment.

- Additional site specific rehabilitation requirements were imposed on the site by regulatory agencies. These requirements had increased the required rehabilitation standards to in excess of those estimated using the workbook cost estimation approach used at the time.

The sites discussed above represent only a small sample of mines where relevant information for this study could be obtained. However, they show that in the past, security bonds have been significantly underestimated in NSW for a variety of reasons. In cases where mines have become bankrupt, significant liabilities have passed to the government and the NSW DPI-MR has listed on their website a total of over 570 derelict mines which have been handed to the government and are currently managed as part of the Derelict Mines program.

There are relatively few sites in NSW that have been rehabilitated by operators where actual costs for rehabilitation can be compared to initial cost estimates. The DPI reported one open cut mine in NSW which provided an example where the mining lease for a successfully returned to the DPI-MR with the site fully rehabilitated by the operator. The security bond for the mine at the time of rehabilitation was approximately $30-40 \%$ of the actual cost to the operator. Another (underground) mine more recently rehabilitated was reported in local press to have cost four times the operators own original estimate which was partly due to unforseen issues arising during the rehabilitation.

If the DPI-MR had been required to complete the rehabilitation due to the companies defaulting on their responsibilities for rehabilitation, the total decommissioning and closure costs may have been significantly more to cover for project management fees, mobilisation of contractors and other additional costs relating to third party management of the mine closure process.

\section{ASSESSMENT OF BOND CALCULATION METHODOLOGIES}

With the aim of investigating potential underlying causes for the failure of the government to hold sufficient Security for closure, in 2002, the DPI-MR (then Department of Mineral Resources - DMR) commissioned URS to undertake a study into their security review process, which included benchmarking of processes against other agencies in Australia and worldwide.

The scope of work included benchmarking of the DPI-MR Security Review Processes against requirements of other similar agencies both interstate and overseas and review of DPI-MR process for estimating rehabilitation costs against best practice. 


\subsection{Methodology}

The following reports on the approach used to conduct the study. It is acknowledged that the study was conducted in 2002, hence some outcomes of the review may have changed now, however, the majority of the findings are still considered relevant.

\subsubsection{Desktop research}

Internet research was conducted to gain initial information on interstate and international security bond processes. Agency websites, legislation and guidelines, industry body publications, codes of practice and related reports were reviewed as part of the study.

\subsubsection{Interstate and international interviews}

Discussions were held with nominated personnel in interstate (Australian) and international agencies to clarify desktop research and gain additional insights on trends, best practice and innovative approaches. Interviews with the organisations listed below were conducted by telephone and supplemented with written communication where appropriate.

\section{Table $1 \quad$ Australian and international contributors to the study}

\begin{tabular}{|l|}
\hline Department/Organisation \\
\hline NSW Minerals Council \\
\hline $\begin{array}{l}\text { Department of Natural Resources and Environment, Victoria (Now the Department of Primary } \\
\text { Industries) }\end{array}$ \\
\hline Environmental Protection Agency, Queensland \\
\hline $\begin{array}{l}\text { Department of Minerals and Petroleum Resources, WA (Now the Department of Industry and } \\
\text { Resources (DoIR)) }\end{array}$ \\
\hline Department of Business, Industry and Resource Development, Northern Territory \\
\hline Chamber of Mines of South Africa \\
\hline Department of Mineral and Energy Affairs, South Africa \\
\hline Department of Infrastructure, Energy and Resources, Tasmania \\
\hline Ministry of Northern Development and Mines, Ontario \\
\hline Minister of Energy and Mines, British Columbia \\
\hline
\end{tabular}

\subsubsection{Benchmarking}

Assessment criteria were developed to benchmark security bond processes and allow an objective review.

Typically, the objective of benchmarking processes was to assess existing processes against best practice. However, the review indicated that best practice was heavily influenced by the risk adversity of respective governments. The balance of factors such as minerals investment, economic development, political influence, rising community standards and rationalised department costs served to define what best practice was for each agency. Consequently, a clear definition of best practice was not easily identified.

Benchmarking was further complicated by the immense variation in mining industries between States and Countries. The number of mines, size of mines and type of activities included under mining legislation (eg mining versus extractive industries) limited the value of direct comparisons between systems. 


\subsubsection{DPI-MR documentation review}

A review was conducted of key documents provided by the DPI-MR, including policies and procedures, bond calculation processes, data on security bond forfeits, internal reviews and relevant literature.

\subsubsection{DPI-MR interviews}

To supplement data from the documentation review, discussions were held with nominated DPI-MR personnel in the Mine Safety and Environment Division and the Titles Branch. The discussions served to clarify existing knowledge and provide a forum to voice views, perceptions and suggested changes.

\subsection{Key Findings of the Review}

The key findings of the review included that:

- Responsibility for security bond calculations was increasingly being delegated to operators/title holders. A number of agencies had implemented this approach, while at the time the DPI-MR did not require titleholder calculations. A key recommendation was that mine operators have the responsibility for "self assessment" of the total costs required for rehabilitation and closure.

- Many agencies did not hold sufficient securities to cover potential mine closure liabilities. The deficiency of cover varied significantly across states and countries, with many acknowledging that low security bonds were the result of a political or commercial decision influences on the agency.

- There was a trend toward annual security bond reviews.

- There was generally a lack of quantitative data measuring the accuracy of security bond processes across many agencies.

- Flexibility, particularly in the management of security bonds for older mines, was prevalent and may have lead to the actual closure costs for the operation being underestimated.

- There was a recognition in the majority of agencies that liabilities must be balanced with social and economic benefits of existing mines and continued minerals investment.

- There was a lack of information available on total liabilities managed by agencies and the accuracy of the rehabilitation estimates used by agencies. The lack of this quantitative information, the high variability among agencies in terms of mining operations within their jurisdictions, and a lack of data regarding third party comparisons with agencies calculation methodologies, made a direct comparison of the performance very difficult.

The study indicated that at the time, very few agencies had a robust process of accurate rehabilitation estimation and enforcement of total rehabilitation bonds based on accurate cost estimates such that they could be considered to represent "best practice". While comparisons were difficult for reasons previously mentioned, the DPI-MR processes were considered to be representative of the standard of many other agencies.

As a result of the study URS and GSSE were commissioned by the DPI-MR to develop a Rehabilitation Estimation Tool to provide to operators so as to assist them in developing a more accurate, thorough and consistent approach to closure cost estimation than that used previously by the DPI-MR. The Tool was developed in 2004. The following sections defined the approach used in developing the Tool.

\section{DEVELOPMENT OF THE REHABILITATION ESTIMATION TOOL}

The key steps in developing a Rehabilitation Estimation Tool were as follows:

- Review of tools and guidelines in use throughout Australia and key mining countries around the world.

- Facilitation of a workshop of mining experts from within URS and GSSE across a range of technical disciplines and experience to provide input and agree on an approach. 
- Use of experience of the project team to develop an approach based on the above inputs.

\subsection{Review of Existing Tools and Guidelines}

Further to the research conducted by URS in 2002, this 2004 review focussed on operator-prepared closure cost methodologies applied interstate and overseas. Agency websites, industry body publications, and industry approaches to closure cost estimations were reviewed as part of this study. Documentation was supplemented with informal telephone discussions with nominated personnel in interstate and international agencies to clarify desktop research and gain additional insights on closure cost methodologies. The results of the review provided a context for the development of the Tool.

\subsection{Various Applications for Rehabilitation Cost Estimates}

There are a number of rehabilitation cost estimates that may be applicable for a mine, depending on the purpose of the estimate. These include:

- End of life of mine closure: in this scenario the mine closure can be planned over a long period with initiatives such as continuous rehabilitation reducing the overall closure costs. This generally applies where the operator of the mine undertakes the required decommissioning and closure activities.

- Closure Costing for accrual or mine planning purposes: Costs estimates over a period of time may be required for various mine planning and accrual scenarios.

- Closure cost estimations using a risk based approach such as probabilistic costing: This approach allows for uncertainties to be accounted for in the overall cost estimate.

This paper has considered only the estimate that is appropriate for the costs that would be incurred by government in the event of an unplanned mine closure and subsequent passing on of all liabilities to the government. In this scenario the government would not be in a position to rely on an established operator to conduct the rehabilitation works. The rehabilitation costs would need to consider costs for third party contractors to undertake the required works which would include mobilisation, project management fees, costs related to limited site knowledge and from the discontinuity with former operations.

While the Closure Tool developed by URS/GSSE can be used or adapted to cover these approaches, the primary purpose of the Tool was to estimate closure rehabilitation costs for the purpose of assessing security bonds by the appropriate regulatory agency.

\subsection{Key Attributes for a Successful Rehabilitation Cost Estimate Tool}

In developing the Tool, criteria defining a successful tool were developed through a brainstorming approach by a panel of mine rehabilitation experts. The key criteria were defined as follows:

- The Tool must be simple enough for all types of operators to use it, without being too simple such that accuracy is lost by not being thorough enough to explore all closure activities.

- The Tool must be easy to understand and use (i.e. minimise the need for detailed volume calculations and rely more on area and length based assumptions).

- The Tool must be adaptable to a wide range of mine types and sizes.

- Operators with significant or limited resources must be able to use the Tool.

- The Tool must be able to consider site specific issues that were not common to all sites but had the potential to significantly increase the rehabilitation liability (e.g. Acid Mine Drainage or located in a sensitive environment such as the Sydney Catchment area).

- The Tool must be easy to review by DPI-MR Officers tasked with reviewing Bond estimates.

- The Tool must compliment or be in line with existing DPI-MR methodologies.

- The Tool should be automated to allow consistency, ease of calculation and reproducibility. 
- The Tool needed to consider third party operator costs including activities such as mobilisation and project management.

- Generic rates for rehabilitation activities would need to be provided.

\subsection{Approach in the Tool Development}

A key approach taken in the development of the Tool was to separate mines and other extractive industries into seven (7) categories based on the nature, size and scale of the operation. Operators are required to choose the most suitable category for their site and relevant spreadsheets are automatically generated that list and provide rates for the most likely closure activities relevant to that site.

Once the category is selected the Tool is presented so that it splits the mine into separate management areas that typically have similarities in rehabilitation requirements or treatment to meet the required post mining landuse. These areas are called "Domains" and they typically include areas such as detailed below.
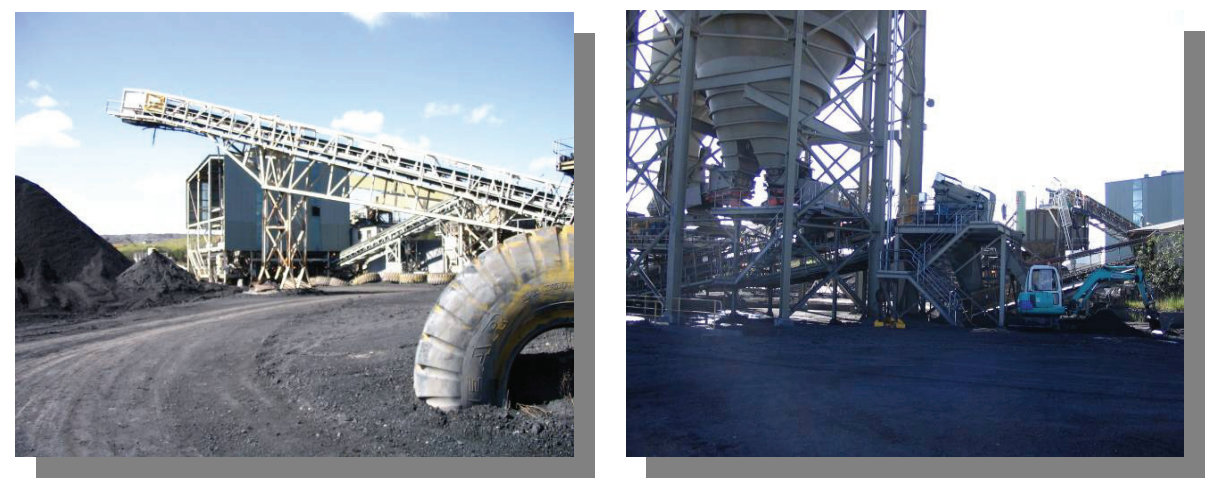

Figure 1 Infrastructure - typically this includes administration buildings, workshops, processing plants and transport infrastructure such as rail loading and roadways
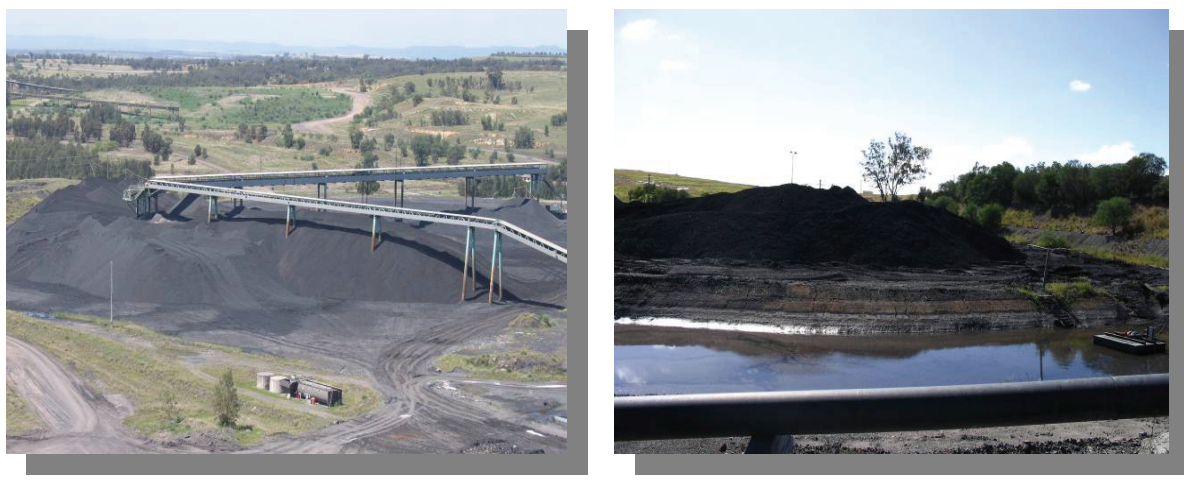

Figure 2 Run of Mine (ROM) and product stockpile areas - typically this includes stockpiles around the processing plant as well as satellite stockpiles that may be around the mine. It would also include areas such as heap leach pads 

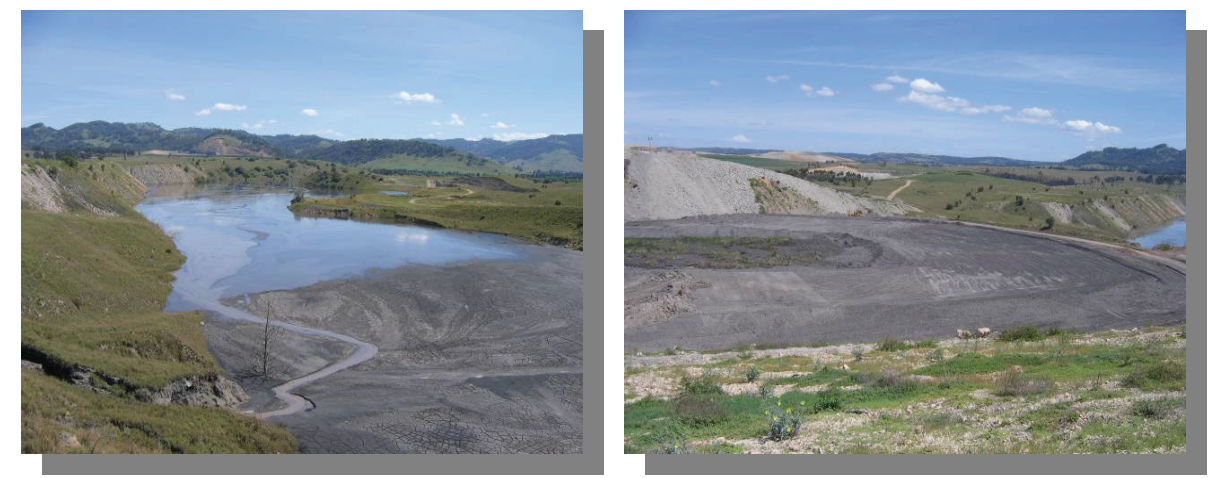

Figure 3 Tailings storage facilities - includes coarse and fine tailing (as applicable) disposal and management areas
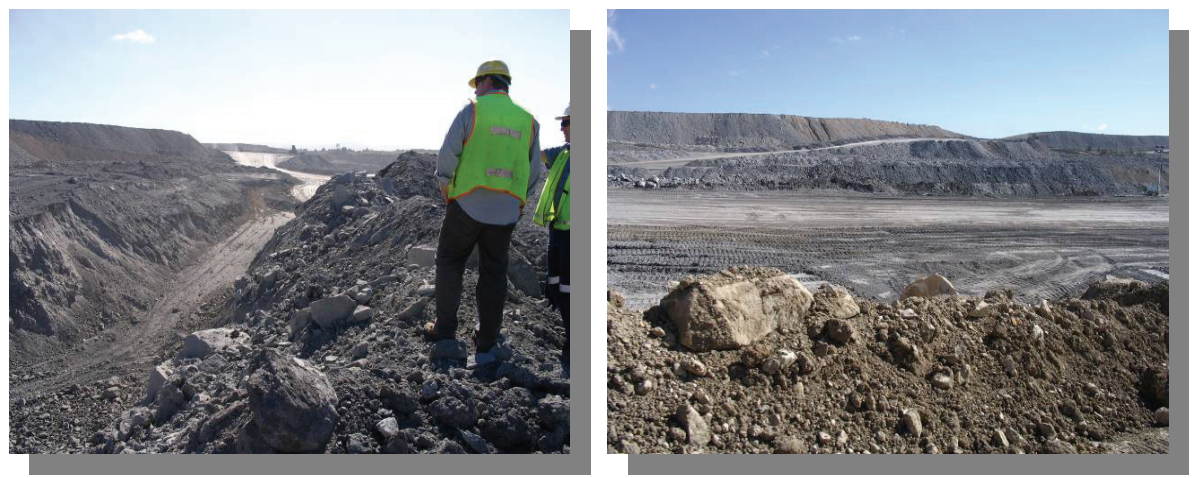

Figure $4 \quad$ Overburden and waste rock dumps - includes all waste dumps, whether they be in-pit or out of pit depending on the nature of the site
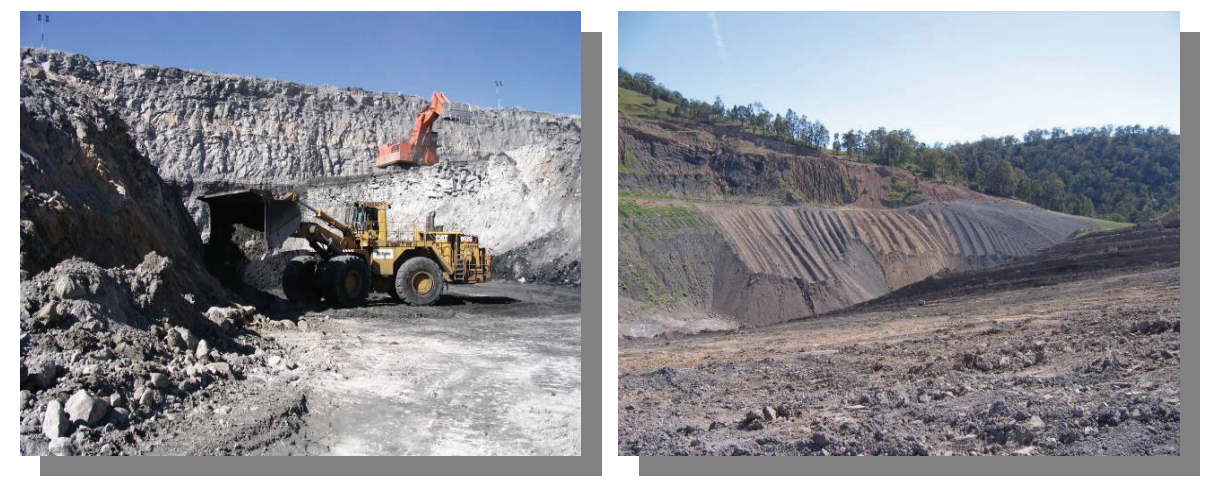

Figure 5 Active operational areas and voids - includes void management and active mining areas of the operation including any access ramps or associated roadways 

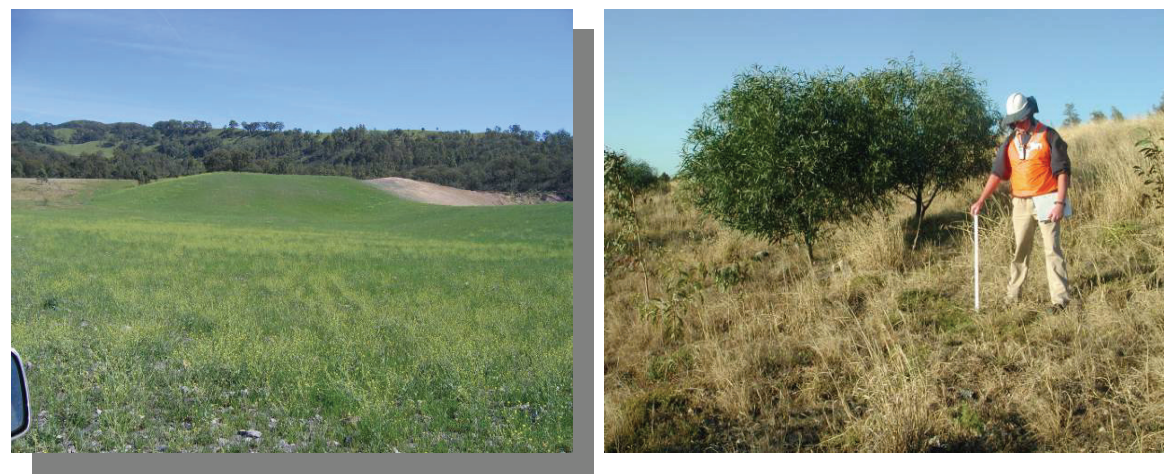

Figure 6 Successful and ongoing rehabilitation areas - this includes all areas that have either been successfully rehabilitated or are at some earlier stage throughout the rehabilitation process

Figure 7 provides an example of a typical open cut mine layout showing the allocation of Domains considering areas of like rehabilitation approach or treatment. For each Domain area, a number of generic activities are listed as line items within the tool. These line items generally describe what activities are typically required within the Domain in order to meet closure requirements for a given site.

MS Excel was seen as the most appropriate format for the Tool as it was considered relatively simple to use, functional given the objectives of the Tool, and is commonly available. The operator is required to input unit amounts (typically linear and area based information) for the relevant activities and then costs are generated automatically. There remains an onus on the operator to include all relevant costs related to closure, whether or not prompted by the spreadsheet Tool.

Figure 8 is an extract from the NSW DPI-MR tool that shows the typical layout of the Domain spreadsheet. Within each Domain area there are a number of Management Precincts which are generally divided into the key activities required for successful decommissioning and closure.

\section{$5 \quad$ TRIAL AND IMPLEMENTATION OF THE TOOL}

Trial and implementation of the Tool was managed by the NSW DPI-MR and included:

- Issue of the Tool to selected mines for trialling and feedback (2005).

- Issue of the Tool to mines where the Mining Operations Plan (MOP) was due for renewal (2005 and 2006).

- Requirement for all mines to use the Tool to assist in security bond calculations after 1 July 2006.

Feedback obtained during the trial and implementation of the Tool included:

- That there has been a general to significant increase in rehabilitation cost estimates by using the Tool compared to previous cost methods used by the NSW DPI-MR. This has lead to increases of Security Bonds across many mines. There was no or limited feedback indicating that costs estimated using the Tool were excessive.

- There has been some informal support from Environmental Officers as the costs highlighted by the Tool provide a basis for up front proactive management of mine activities with an aim to reduce longer term liabilities. 


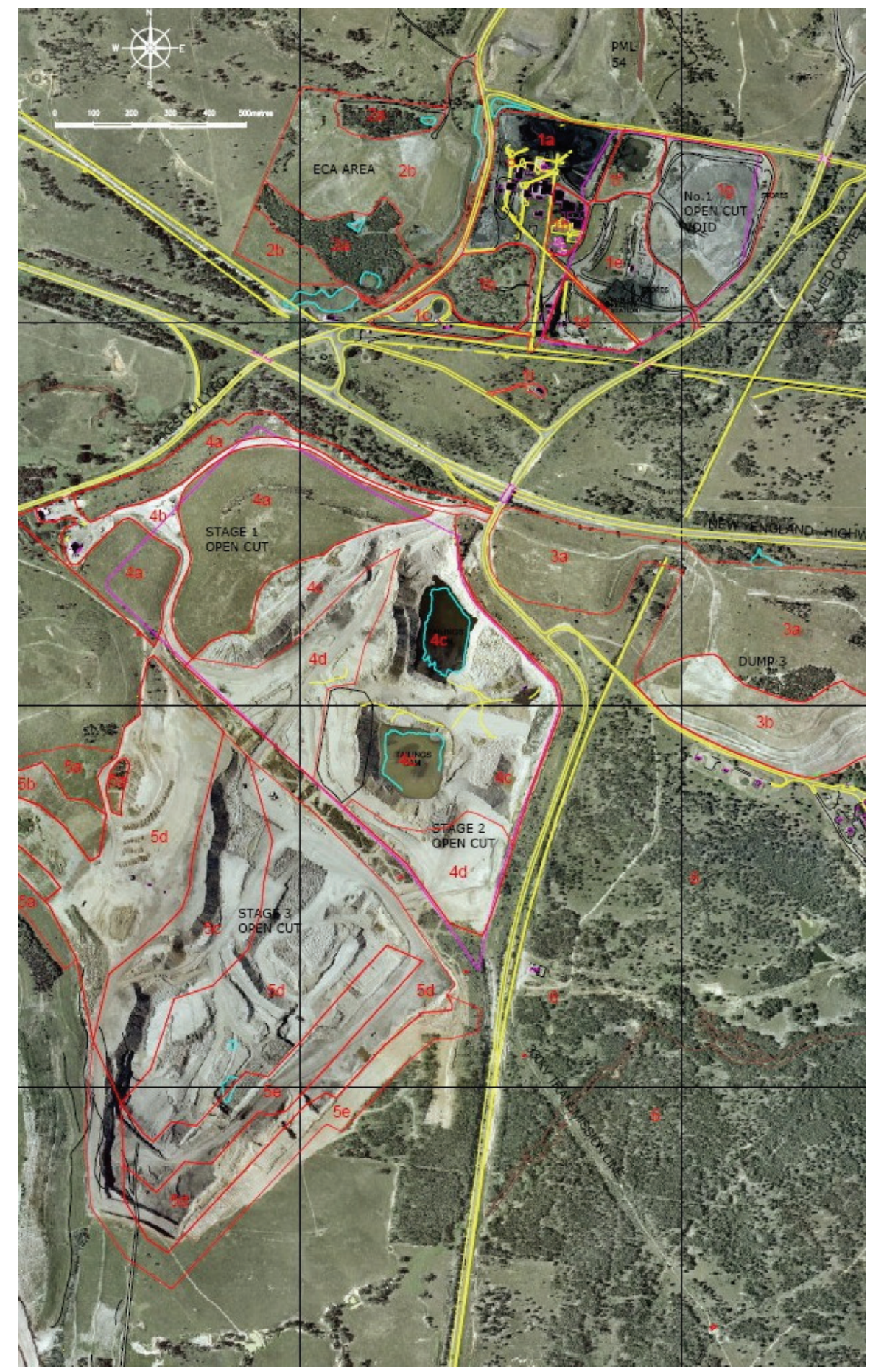

Figure 7

Plan showing the concept of domains of similar areas 


\section{Domain 3: Overburden \& Waste Dumps}

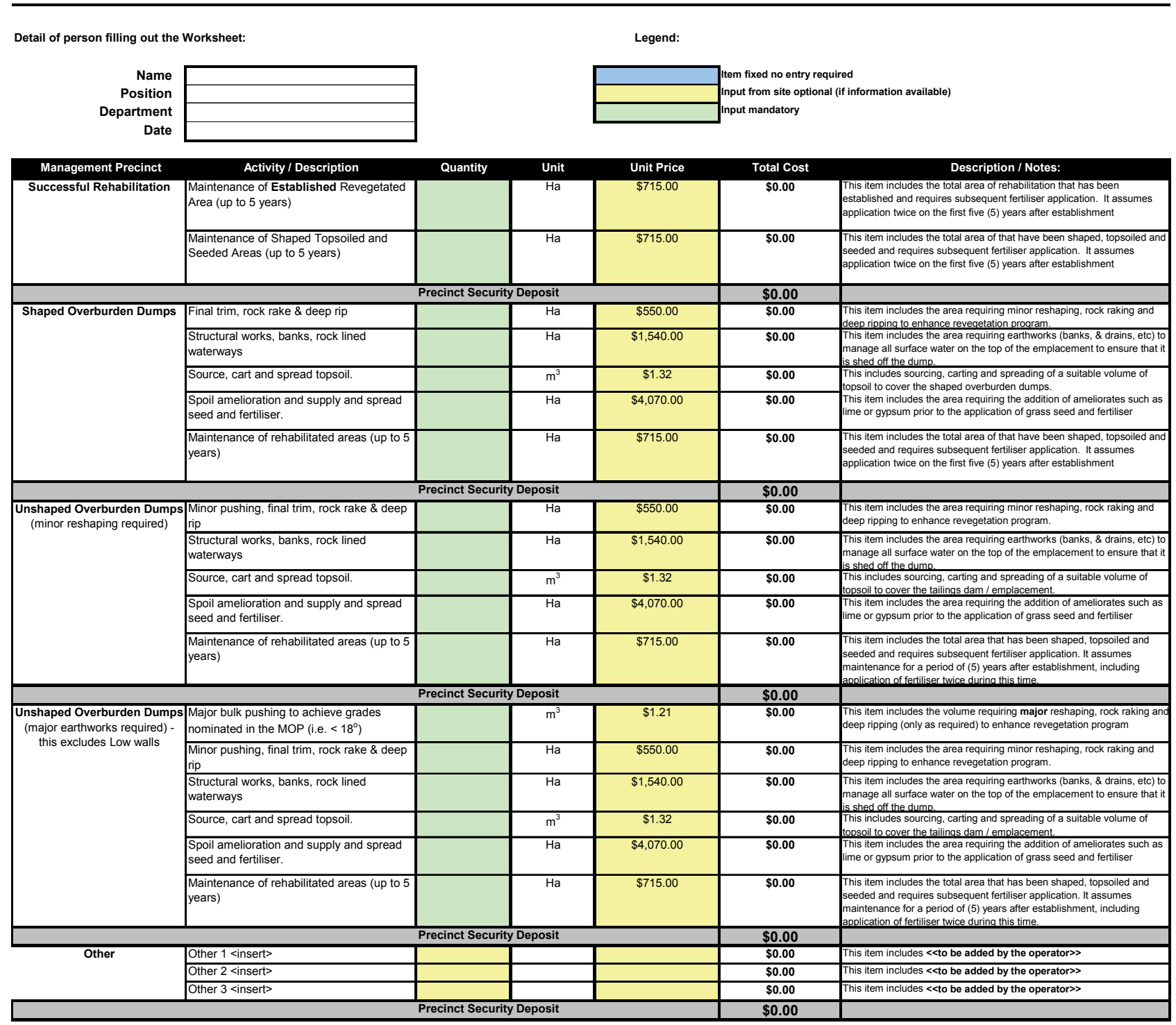

Total Security Deposit for the "Domain"

$\$ 0.00$

\section{Figure 8 Typical layout of the Domain spreadsheet}

- That some companies are doing there own detailed cost estimates according to internal standards and submit these to the DPI-MR, rather than duplicating their work by using the Tool as well. This is seen as a beneficial outcome as the operators costing are now more closely linked to Security Bond calculations. It is important to ensure that this process is undertaken on the basis of "third party" costs and not the current operational costs.

- In the first instance, there is some operator "investment" to go into the Tool to get reasonable numbers. Following use and modification of the Tool it becomes easier as much of the data can be retained.

- There has been robust discussion on rates specified in the Tool. This is understandable as rates cannot be specified as absolute for all situations. The Tool allows for operators to use their own rates, subject to their justification as being considered appropriate by the NSW DPI-MR. 
- A number of comments were received regarding technical issues with the use of the Tool. These included inserting a table to summarise the general rates and clarification for the basis of rates. The NSW DPI-MR has made some changes to the Tool according to the Feedback received.

\section{IMPROVING THE REHABILITATION COST ESTIMATION TOOL}

The Tool has since been adapted for the Victorian DPI to assist in their management of mines and extractive industries. Following modification to the Tool, the Tool has been trialed internally by the VIC DPI. Significant improvements have made based on the NSW DPI feedback and further review by VIC DPI.

The key changes have included:

- Improved layout and better use of the functionality of MS Excel.

- Adapting the Tool for use by small and large quarries (more typical of Victoria).

- Including exploration as a separate mining related activity.

- A reassessment and verification of some of the rates used.

- Inclusion of a separate column for operators to include their own rates. If alternate rates are used, the cell is highlighted to prompt increased scrutiny of the rate by DPI officers.

- Requiring the operator (rather than the DPI) to identify whether an activity is applicable to their site and therefore being included in the cost estimate.

- The development of a separate rates table to allow ease of altering a rate by the DPI. This table then links back to all other aspects of the spreadsheet.

URS/GSSE expect that in the future the Tool will be further improved through ongoing use and increased focus on aspects of mine closure not currently considered by the Tool in detail. This could include coverage of socio-economic costs, the use of probabilistic costing based on risk assessment, and further refinement of the process. In addition, the format of the Tool may be improved by use of a database system, allowing more robust compilation and interrogation of mine closure information across all mines and quarries in a given state or area.

Based on the studies undertaken, it is our view the Tool represents best practice in Security Bond estimation. Ongoing improvement of the Tool will be required to maintain this situation.

\section{ACKNOWLEDGEMENTS}

URS and GSSE would like to acknowledge the NSW DPI-MR and VIC DPI in undertaking the studies that led to the development of the Tool with an aim to better improve the management of government liability in relation to unplanned mine closure.

We also acknowledge the significant input of Environmental Officers and others who have trialled and used the Tool, particularly those that have provided feedback to the DPI-MR on its use.

\section{REFERENCES}

URS Australia (2004) Options Assessment Paper, Review of Security Bond Estimation Processes.

URS Australia (2002) Review of Mine Rehabilitation Security Processes.

NSW Department of Primary Industries (2005) Managing Derelict Mines, Primefact 22. 